\title{
A cross-sectional study assessing the alarming prevalence of burnout among physicians in a developing country facing a combination of a COVID-19 Pandemic and an economic collapse
}

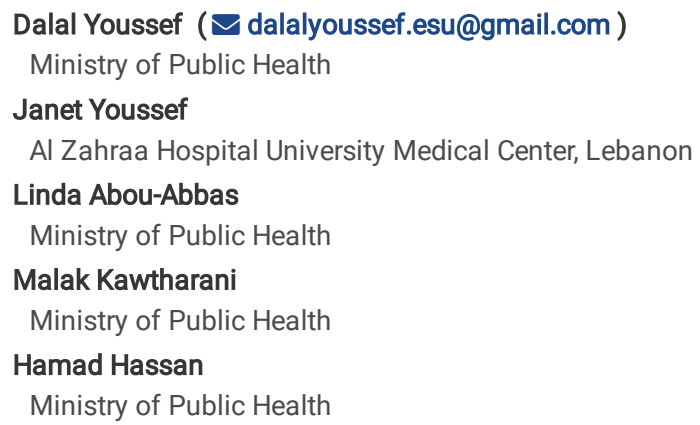




\section{Abstract}

Background:

Burnout among physicians is a serious concern that cultivates its seeds during their education and matures in their daily practicing life. Lebanese physicians were particularly at high risk of burnout since they confronted a mixture of overlapping crises.

Objectives:

This study aimed to assess the prevalence of burnout among Lebanese physicians and to investigate its associated factors. It targeted also to explore the combined effects of the pandemic and the economic crisis on burnout.

Methods:

A web-based cross-sectional study was conducted among Lebanese physicians over December 2020 using a snowball sampling technique. Self-reported data were collected electronically through an anonymous questionnaire that included information on socio-demographic characteristics, work-related variables, and 4 scales: fear of COVID-19, threat perception, InCharge Financial Distress/Financial Well-Being, and the Copenhagen burnout inventory (CBI). CBI scale cut-off score of 50 was used to evaluate the prevalence of burnout. Multivariable linear regression analyses were carried out to identify the factors associated with burnout.

Results:

A total of 398 physicians participated in the study. The majority of them were male (52.8\%), married (60.1\%), and aged between 40 and 49 years (43.2\%).Moderate and High level of burnout hits $90.7 \%$ of the Lebanese physicians where personal, work-related, and client-related burnout were detected among $80.4 \%, 75.63 \%$, and $69.6 \%$ of them respectively. A strong association was found between the higher level of burnout and female gender, younger age, being single, having a dependent child, living with an elderly or having a family member with comorbidities, and insufficient sleeping hours. Physicians' specialties, working in a public health facility, limited years of professional experience, lack of previous experience in pandemic, and extensive working hours were also associated with increased burnout. Furthermore, low income, working in the frontline, higher threat perception, and fear of COVID-19 were contributing to higher burnout. However, financial wellbeing, altruism, having good health, and previous history of COVID-19 were significantly associated to lower burnout. The combined effect of threat perception and financial hardship significantly increased the level of burnout.

Conclusion:

The huge burnout level detected among Lebanese physicians raises alarm about the seriousness of the current situation and urges the health authorities to take prompt action to enhance the physicians' wellbeing.

\section{Background:}

In recent years, burnout syndrome has been a major concern widely discussed in the area of occupational health [1,2]. It was described as a state of psychological exhaustion resulting from extended exposure to a stressful work environment [3]. It may occur in a very wide range of work contexts, and in particular in demanding jobs such as healthcare providers [4-6]. Healthcare workers (HCWs) belong to the most devoted servants to humanity which gives them a lifetime professional gratification [7, 8]. However, healthcare was listed among the top high-stress professions that provoke a high level of burnout [4]. Despite the variation of the extent of burnout among HCWs, several studies found that all medical staff including physicians [9, 10], pharmacists [11], nurses $[12,13]$, and lab technicians [14] experienced burnout.

Of note, physicians are among the top potential candidates for burnout [15]. Notably, burnout among physicians begins to cultivate its seeds during their education period, goes along with the residency, and finally matures and crowned their practicing life [16-18]. This could be resulting from the exposure of physicians to high levels of work distress, persistent tension, extensive working hours, a wide range of tasks, and interaction with patients and their relatives, and colleagues as well $[19,20]$. They also deal regularly with several complex situations, including responsibility for the health of patients, high patients' and family expectations, patients' and families' aggressive behaviors complaints and high expectations, and coping with death and injury [21-23]. Physicians who encounter these issues are more likely to have psychological and physical exhaustion which lead them to be cynical about their work [24-26].

Several studies conducted before the COVID-19 pandemic have indicated a high prevalence of burnout among physicians [27]. The prevalence of burnout among physicians varies between countries; ranging from 3.7-54.1\% [28-30]. In Arab countries, such prevalence ranged from 12.6-41.94\% [31]. Another study estimated that one in every three physicians would suffer from burnout at a given time [32, 33]. Of note, burnout among physicians has devastating personal and professional consequences and could incite them towards turnover, early retirement, and poor job performance [34, 35]. Besides, it impacted negatively the quality of care provided to patients and increased the risk for medical errors [36-38].

In the era of the COVID-19 pandemic, the prevalence of burnout among physicians is snowballing. Physicians experienced ever-increasing pressure in their daily lives, particularly at their work [39-41]. This upsurge was reported in numerous studies conducted worldwide [42]. Similar to other countries, Lebanon experienced many challenges imposed by the COVID-19 pandemic on its healthcare system which was already in a fragile state even prior to the pandemic [43], the economic collapse [44], and the Beirut blasting [45]. It was overwhelmed by the humanitarian crisis revealed by the influx of more than one million Syrian refugees [46]. However, the COVID-19 pandemic overlapped with an economic crisis that has its roots in the aftermath of the civil war goaded by corruption and mishandling of the country's resources [47]. This economic crisis was ranked by the World Bank among the world's three worst crises since the mid-1800s affecting living standards where the Lebanese pound has lost more than $90 \%$ of its values since fall 2019 [48]. This was later followed by the

Page $2 / 23$ 
devastating Beirut blast, which was coupled with a meteoric soar in COVID-19 infections and hospitalizations where ICU occupancy in the hospitals touched $95 \%$ in January 2021 [49]. Physicians, among other HCWs, bear the large toll of the pandemic [50]. In addition, the growing number of physicians diagnosed with COVID-19 unveiled gaps in policies and laws intended to warrant physician safety such as coverage for healthcare, disability, and death [51]. As a result of these consecutive and combined events, Lebanese physicians are leaving to find a better life elsewhere [52]. In such a typical context of multiple calamities that fueled mental health problems and burnout; it is of great interest to assess the level of burnout among Lebanese physicians and to understand its determinants in order to prevent and reduce such syndrome. Of note, concerns about pandemic [53] and financial wellbeing [54] were able both to instigate psychological illnesses and could interact and increase the burnout among physicians.

The present study aims to assess the prevalence of burnout among Lebanese physicians stranded amid the mixture of crises, along with how sociodemographic factors, work-related factors, economic factors, and pandemic-related factors affect the intensity of burnout. Besides, we targeted to assess the combined effects of the COVID-19 pandemic and economic crisis on burnout.

\section{Methods: \\ Study design and population:}

A web-based quantitative cross-sectional study was conducted among Lebanese physicians from the eight Lebanese provinces using a snowball sampling technique. It was conducted over December 2020. Participants were identified via professional groups and health facilities and electronically invited to participate.

Physicians were contacted via phone call and notified about the survey and its purpose. Upon their agreement to participate, an online questionnaire using a Google form was sent to them via emails or WhatsApp as per their preference. They were invited if possible to disseminate the link of the survey among their colleagues. All practicing Lebanese physicians who had access to the internet were eligible to be part of the study. Physicians who are not practicing currently, those who were out of the country at the time of the survey, retired physicians, interns, and those who refused to give informed consent were excluded.

\section{Sample size calculation}

Using an estimated population of 10,918 physicians [55], an expected response of 50\%, a $95 \%$ confidence level, and an estimated absolute error of $5 \%$, the requisite sample size was calculated using the RAOSOFT digital sample size calculator which yielded the least required sample size of 372 participants.

\section{Ethical consideration}

The study has no foreseeable risks, and written informed consent was obtained in an electronic format. All methods were performed following the relevant guidelines and regulations and the study was exempted from ethical approval in the Lebanese Ministry of Public Health. Respondents were reassured that their participation is voluntary All information were gathered anonymously and handled confidentially. The study design assured adequate protection of study participants and do not imply any risk for them. No reward was received by respondents in return for participation.

\section{Instrumentation:}

A questionnaire was developed in the Arabic and the English languages through Google forms. The utilized scales used were translated into Arabic following the guidelines concerning the forward and backward translation. A consensus was used to resolve inconsistencies between the original and translated versions. A pilot survey was also conducted on 15 physicians, and reformulations for some questions were made throughout its course. The answers to the pilot survey were excluded from the final data of this study. The finalized anonymous, self-administered questionnaire took 10 to 13 minutes to be completed and consisted of three sections: (a) basic sociodemographic characteristics, (b) work-related and exposure to COVID-19 variables, and (c) the measurements

The first section collected sociodemographic data of the participants, including gender, age, marital status, specialty, urbanicity, health status, and living conditions. It also included questions about the history of illnesses and the health status of people living with the participant. Physicians were also asked about the type of health facility where they worked. The second section covered the topic of exposure to COVID-19 in addition to work-related variables. Physicians were queried to answer on whether they have worked in the frontline, treating COVID-19 patients, been tested or diagnosed as COVID19 case, had a family member or a colleague infected by COVID-19. The third section consisted of 4 validated scales to objectively assess financial well-being, threat perception, fear of COVID-19 (FOC), and burnout. The scales were used after requesting permission from their copyright owners when required.

\section{1-The perceived threat (TP) and altruistic acceptance of risk questionnaire:}

This tool was developed by Chong [56] consisted of 10 items where nine of these items described HCWs' perception toward COVID-19 threat and one item asking for altruistic acceptance of COVID-19 risk. Ratings were given based on a five-point Likert scale from 1 (strongly disagree) to 5 (strongly agree). Responses were dichotomized into positive responses 'agree' or 'strongly agree', while 'strongly disagree', 'disagree', and 'not sure' were considered negative. The Cronbach alpha of this scale was equal to 0.703.

\section{2-The FOC scale:}

This tool developed by Ahorsu consisted of 7 items [57] and scored on a five-point Likert scale from 1 (strongly disagree) to 5 (strongly agree). The score is calculated by summing the answers and ranged from 1 to 35 . Higher scores indicated a large extent of fear from COVID-19. The Cronbach's alpha for this scale was 0.769 .

\section{3- The InCharge Financial Distress/Financial Well-Being scale (IFDFW)}


This tool was developed by Prawitz [58] including eight items measuring the perceived financial distress/financial well-being on a linear scale from 1 to 10. Higher scores reflect lower financial distress and higher well-being. The Cronbach's alpha for this scale was 0.85 [59].

\section{4- The Arabic version of Copenhagen Burnout scale A-CBI:}

The validated Arabic version of the CBI that consisted of 19 items was used (Youssef et al. submitted). It evaluates personal-related (PB) (6 items), workrelated (WB) (7 items), and client-related (6 items) (CB) burnout. Participants were asked to rate how often they felt exhausted. Ratings were given based on a five-point Likert scale. Each item was scored from 0-100 ( $0=$ never, $25=$ Seldom, $0=$ Sometimes, $75=0$ ften, $100=$ Always). Of note, some questions were answered using another five-point Likert scale (to a very high degree, to a high degree, somewhat, to a low degree, to a very low degree). Mean items score was calculated per scale. A cut-off of 50 was used to assess the prevalence of burnout among physicians. A score of more than 50 is considered high or moderate burnout level whereas a score less than 50 signify a low burnout level or its absence. The score was valid and reliable according to many previous studies [59]. In our study, the Cronbach's alpha of this scale was equal to 0.879 .

\section{Statistical analysis:}

The generated data on excel was transferred to SPSS ${ }^{\circledR}$ software (Statistical Package for Social Sciences) version 24.0 for analysis. No missing data were recorded since the response to all questions was mandatory. For descriptive analysis, frequency and percentage were used for categorical variables, the mean and standard deviation for quantitative variables. The normality distribution of $\mathrm{CBI}$ items was confirmed by calculation of skewness and kurtosis values. $(<1)$ [60]. The Student's T-test was used to compare the means between 2 groups. One-way analysis of variance ANOVA was used to compare between three groups or more, after checking for homogeneity of variances. A Spearman's correlation was used to test correlation between used scores with burnout subscales. To estimate effect size, the Eta squared was used. All variables that showed a p-value 0.2 in the bivariate analysis were included in the multivariable analysis as an independent variable. Four linear regressions using the stepwise method were conducted to identify the correlates of each of the $\mathrm{CBI}$ scales. P-value 0.05 was considered statistically significant. To assess the interaction between the TP and the financial wellness (IFDFW) scales, the estimated marginal means were calculated for burnout among subjects according to their TP of COVID-19 and IFDFW (high/low categories). The dichotomization of the two variables (TP and IFDFW) into high and low categories was done according to the median of each scale.

\section{Results:}

\section{Baseline information of the participants:}

A total of 398 physicians participated in the survey. The majority of them were male (52.8\%); married (60.1\%), aged between $40-49$ years old (43.2\%), and residents of Mount-Lebanon province (34.7\%). Around half of participants had currently a dependent child (47.7\%) or were living with the elderly (53\%) or a family member with comorbidities at home (53.8\%). More than two-thirds (69.85\%) of surveyed physicians had a professional experience larger than 10 years and a previous experience in working in pandemic (74.12\%). The highest percentage of respondents were working in the frontlines (62.1\%) and $51.9 \%$ of them were caring of COVID-19 cases. Only $15.3 \%$ of them had a previous history of COVID-19. However, $44.2 \%$ of the participants had a family member diagnosed with COVID-19 and $90.2 \%$ of them had a colleague diagnosed with COVID-19 (Table 1). Of note, the majority of surveyed physicians (39\%) were specialized in internal medicine (Figure 1)

\section{Description of the scales:}

$\mathrm{CBI}$ had a mean of $65.34(\mathrm{SD}=17.39)$ while the values for TP scale, FOC scale, and IFDFW were $35.53(\mathrm{SD}=2.88), 17.88(\mathrm{SD}=1.4)$, and $22.85(\mathrm{SD}=7.64)$ respectively. The normality of the scales was assumed since skewness and kurtosis were lower than 1 and the sample size larger than 300 . The used scales showed good reliability; IFDFW ( $a=0.85)$; FOC $(a=0.769)$; TP $(a=0.703)$ and CBI $(a=0.879)$. The lower scores of IFDFW reported in all items of the scale

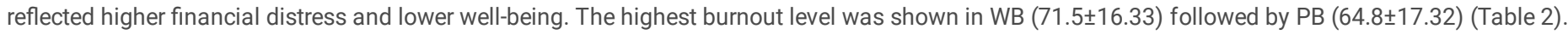

\section{Prevalence of burnout among Lebanese physicians}

Moderate and high level of burnout was detected among $90.1 \%$ of surveyed physicians, where $19.1 \%$ had a high level of burnout. PB ranked first among other burnout aspects (80.5\%) with $45.8 \%$ of physicians reporting high PB levels. As for WB, it was detected in its moderate and high level among more than threequarters of physicians (75.6\%), where $60.3 \%$ exhibited a high level of WB. Moderate and high CB was found among $69.6 \%$ of respondents (Figure 2 ).

\section{Socio-demographic characteristics and burnout}

Female gender, younger age, being single or divorced, and physicians who had a dependent child and those who live with elderly and family members with comorbidities had a significantly higher level of burnout. Similarly, all these sociodemographic variables were significantly associated with a high level of PB, WB, and CB except the age which was not significantly associated with the work-burnout dimension. The largest effect size was observed in age, marital status, and presence of a dependent child at home (Table 3 ).

\section{Economic characteristics and burnout}

Surveyed physicians who have private health coverage and those who subjectively classified themselves as having a low socioeconomic status currently had significantly higher burnout in all its aspects (PB, WB and CB). Besides, physicians who earned less than two Million Lebanese pounds per month and those who considered that pandemic or economic crisis highly impacted their monthly income showed also high burnout. However, financial well-being (FWB) was negatively correlated with high burnout. Regarding burnout, the largest effect size was seen in low economic status after the pandemic and economic crisis, major impact of the economic crisis on the income and FWB (Table 4). 
Physicians working in public hospitals, those with limited professional experience (less than 10 years), and those who lacked from a previous experience during pandemics had significantly higher levels of burnout compared to their counterparts. Furthermore, insufficient sleeping hours, extensive working hours, and physicians' higher perception of COVID-19 impact on their work increased the overall burnout among respondents. These factors had a large effect size related to the overall burnout. Similar occupational factors were associated with a high Level of BP except for extensive working hours. In addition to the identified professional factors increasing burnout among physicians, working in hospitals located in urban areas had higher WB. In terms of CB, a higher level was associated with health facility type, previous pandemic experience, and extensive working hours (Table 5).

\section{Exposure, perception of COVID-19 threat, fear of COVID-19, altruistic, health characteristics, and burnout}

Having a good health status, a history of COVID-19 infection, and altruism were significantly associated with a lower level of burnout in all its aspects. FOC and higher TP were correlated with higher burnout among physicians. Similarly, participants who perceived a major impact of the pandemic on their daily life and their familial relationship reported higher levels of burnout. The largest effect size was found for the TP of COVID-19, altruistic and COVID-19 impact on familial relationships. Altruism was significantly associated with a decreased burnout in all its aspects (Table 6).

\section{Correlates of burnout and its subscales: a multivariable analysis}

Higher burnout was associated with female gender, younger age, physician specialty, working in public hospitals, higher TP, insufficient sleeping hours, low income, extensive working hours, having a dependent child or family member with comorbidities, and limited professional experience. However, being married, financial wellbeing, good health, history of COVID-19, altruistic, and previous pandemic experience were significantly associated with lower burnout. The full model could explain $76.1 \%$ of the overall burnout. PB was associated with younger age, female gender, having a single or divorced marital status, presence of an elderly, child at home, or family member with comorbidities. Higher TP, FOC, sleeping disturbance, extensive working hours, and low income were associated with higher PB. However, financial wellbeing, altruistic and good health were associated with lower PB levels. The full model could explain $67.2 \%$ of the PB. As for WB, similar factors were associated with higher burnout in addition to the hospital's type. The full model could explain $58.4 \%$ of the WB. In terms of $\mathrm{CB}$, we found that younger age, higher perception of threat, FOC, and low income were associated with higher CB. Similar to other aspects, altruistic and large professional experience and financial wellbeing were associated with a decreased level of CB (Table 7).

\section{Interaction between TP of COVID-19 and financial wellness score}

The multivariate analysis showed a significant interaction between the TP of COVID-19 and the financial wellness (IFDFW) scores on estimated marginal means of burnout. Estimated marginal means showed a significant linear increase of contrasts between the four categories of physicians: those with no TP and IFDFW (Category 0), those with TP and IFDFW (Category 1), those with TP and no IFDFW (Category 2), and those with no TP and no IFDFW (Category 3 ). Compared to physician with no TP and financial well-being $(\mathrm{CBI}=58.9 ; \mathrm{PB}=60.1, \mathrm{WB}=63, \mathrm{CB}=53.5)$, TP of COVID-19 added some burnout (CBI=63.9, $\mathrm{PB}=62.8$, $W B=67.5, C B=55.9)$ followed by a higher increase related to financial distress $(C B I=64.1, P B=65.7, W B=70.5, C B=57.1)$ while the highest increase in burnout was found in subjects presenting high perception of COVID-19 threat and financial distress (CBI=65.7, $P B=67.8, W B=73.1, C B=59.9)(F i g u r e 3)$.

\section{Discussion:}

The COVID-19 pandemic has aggravated the levels of burnout among physicians who had to shoulder the burden of COVID19. Our present study aims to assess the level of burnout among Lebanese physicians along with how sociodemographic, occupational, economic, and pandemic-related factors affect the intensity of burnout. Besides, it aimed to explore the combined effects of the pandemic and the economic crisis on burnout. It is believed that this paper is the pioneer study in Lebanon focusing on burnout during the context of double hit and investigating factors associated with burnout and the combined effect of these crises among physicians.

\section{Main findings:}

A significant burnout level was detected among physicians during these unprecedented times. A strong association was found between sociodemographic variables, occupational, economic, and exposure factors with a higher levels of burnout. However, financial wellbeing, altruism, having good health, and a history of COVID-19 were significantly associated with a lower levels of burnout. The analysis of the combined effect of the COVID-19 pandemic and financial wellness demonstrated that the presence of both TP and financial hardship significantly increased the level of burnout.

Our findings revealed that burnout hits more than $90 \%$ of the Lebanese physicians and around $20 \%$ suffered from a high level of burnout. In addition, more than the third quarter of them expressed PB (mean=64.8) and WB (mean=71.5). As for CB (mean=58.7), it was detected among $69.6 \%$ of respondents (mean=58.7). Several studies documented burnout and its effects among physicians [61-64]. For example, a study reported that $45.8 \%$ of US physicians had experienced burnout [28].

The prevalence of burnout in all its aspects in this study was higher than those reported in other studies. In a systematic review covering 176 studies, an overall burnout of $48.7 \%$ was found [65]. During COVID-19, burnout was prevalent among $57.7 \%$ of Jordanian physicians [66]. Of note, the use of different tools for assessing burnout, impedes the comparison of our results directly with the findings of other previous studies such as the one conducted among Lebanese physicians in 2013 [67]. In comparison with studies using the CBI scale whether before or after the pandemic, our findings were much higher than those reported in these studies. A study conducted among emergency physicians in Bahrein found a prevalence rate of $81.0 \%$ for PB, $69.8 \%$ for WB, and $40.5 \%$ for CB [68]. Another study conducted among German general practitioners showed that one-third of physicians suffered from PB symptoms, one quarter showed WB while $12 \%$ of them reported a high prevalence of $\mathrm{CB}[69]$. 
This crippling effect on mental health revealed by the huge prevalence of burnout among Lebanese physicians was predictable in such a typical context that cumulate the traumatic effect of the COVID-19 [70] and the unprecedented economic crisis. Hence, urgent measures that tackle this tragedy are required to save an already ailing health sector.

Our findings showed that higher burnout was associated with the female gender. There have been contrasting results regarding gender. Some studies reported no gender differences whereas other studies found that females experienced more burnout compared to males [2]. Consistently with our findings, McMurray et al. [71] reported that women physicians had increased odds of burnout when compared to men And Kannampallil et al. also found a higher prevalence of burnout amongst women during the pandemic [72].

Furthermore, this study highlighted the association between younger age and a high level of burnout. Our findings were consistent with the results of a study among Hungarian general practitioners and residents which considered younger age as the strongest predictor of burnout [73]. However, another study conducted among Portuguese physicians reported that younger age and female gender were independent determinants of burnout [74].

Another important aspect of burnout, noticed in our study was that being married decreased the level of burnout. The findings of Shanafelt et al [28] supported our results concerning the presence of a partner (being married) and the decreased risk of burnout [6]. This could be explained that physicians who are supported or feel supported by their partners or loved ones experienced less burnout when compared to those who do not. Interestingly another study showed that spouse support decreased burnout by $40 \%$ [3].

Notably having a dependent child or having a family member with comorbidities were both associated with higher burnout levels. Our results were comparable to those reported by Koh et al. and Maunder et al. both suggest that having children is a predisposing factor to burnout [4, 5]. However, McMurray et al. found that women physicians who had young children to look after reported a decrease in burnout by $40 \%$ [3]. In summary, concerns about contracting the disease and transmitting it to family members were linked to higher burnout and anxiety [75].

In terms of pandemic-related factors, a higher TP was also associated with a higher level of burnout. It is well recognized that intense fear and TP when people experience physical and psychosomatic disorders lead to such anxiety, burnout, and emotional exhaustion [76-78]. The uncertainty surrounding the pandemic in terms of healthcare policy reform and compensation changes could also instigate burnout.

In terms of economic factors, a current low socioeconomic status and income, and negative financial wellbeing were associated with a higher burnout level. Of note, a previous higher socioeconomic status and a current fear of poverty were found associated with higher stress and burnout, whereas current financial wellness was correlated with lower burnout. Such piercing association in low- and middle-income countries is leading to several mental disorders [79]. This was typical of the Lebanese context where physicians with savings in the country's banks were unable to reclaim their money. Moreover, the enormous devaluation in the country's currency led to a loss of more than $80 \%$ in physicians' income [8]. The current situation had detrimental consequences among physicians, including soaring burnout, and psychiatric illnesses $[80,81]$ in addition to an exodus of physicians who left the country searching for stability, financial wellbeing, and safety. It is well known that rising poverty and economic insecurity are associated with stress [54] which in turn, can lead to burnout and demission. In a country in freefall where the economic crisis is expected to escalate, health facilities were in danger of laying off employees, postponing some services, or completely closing their doors.

In terms of occupational factors, our findings showed that internal medicine and infectious diseases specialties of physicians were associated with higher levels of burnout compared with other specialties. The role of specialties as a contributor to burnout in our study may be partly due to differences in exposure to COVID-19 cases as ID specialists, and internal medicine physicians such as pulmonologists and cardiologists were more involved than other physicians in the treatment of COVID-19 cases.

This dissimilarity of burnout among specialties was also highlighted by a meta-analysis conducted by Lee, et al. Besides, our findings highlighted that burnout rates were highest amongst physicians involved in frontline care. This was predictable since their job presented a higher risk of infection since they are in direct contact with COVID19 cases. A study conducted by Kannampallil et al. showed similar results concerning who reported that had a higher prevalence of burnout (46.3\%) among physicians exposed to COVID-19 patients compared to those who were not exposed (33.7\%) [14].

However, other studies conducted among physicians found different aspects [65]. For example, Wu et al and found that medical staff working on the front line had a lower level of burnout compared to those working on usual wards explaining this unexpected trend, by suggesting that frontline workers may have felt a greater sense of control over the situation. Similar to other studies, our findings showed that insufficient sleeping hour and extensive working hours were associated with a higher level of burnout.

One peculiar finding in our study was that working in public hospitals was found associated with higher burnout. In fact, public hospitals were firstly designated by health authorities to treat and isolate COVID-19 patients, hence physicians working in hospitals were more exposed to COVID-19. Given the economic collapse and short of funds, the government was unable to support alone hospitals with much-needed resources and supplies. This called for the support of foreign and local non-governmental aid to import essential supplies and equipment, including personal protective equipment.

In regards to extensive working hours and sleep deprivation, several studies highlighted that sleep deficiency is a key risk factor for burnout among physicians [82]. With the soar of COVID-19 cases, physicians are facing intense workload, extensive working hours, which eventually impacted physicians sleeping hours. A study conducted among HCWs prior to the pandemic showed that $33 \%$ of them were screened positive for the sleeping disorder [17] which was associated with 4-fold bigger odds of burnout.

In addition to the above, limited work experience was associated with higher burnout. Consistently, a Portuguese study reported that HCWs with larger experience were less affected by burnout [83]. Another study conducted among physicians in Lithuania found a significant reverse relationship between work 
and patient burnout and length of employment [84]. However, previous experience during a previous pandemic or emergency decreased the level of burnout. This can be explained that previous experience provides physicians with a sense of confidence and control over the situation and lessens their worries when dealing with patients. Physicians with good health status and previous history of COVID-19 experienced a lower level of burnout. Their good health status and a history of COVID-19 could lessen their concerns about their susceptibility as a previous infection could instigate their sense of being immune naturally.

The role of altruism in decreasing the level of burnout was supported by our study as we found that physicians who accept the risk of caring for COVID19 cases had lower burnout levels in comparison with those who didn't accept this risk. Our results were compatible with the findings of a Turkish study which reported that the burnout level of physicians who were actively involved in the fight against COVID-19 was lower than their counterparts who are not actively involved [85].

Lastly, the combined effect of the threat of COVID-19 pandemic and financial hardship significantly increased burnout levels among physicians. Despite the scarcity of previous studies tackling such a topic, a review supported the effect of economic uncertainty on mental health in the era of COVID-19 [86]. The increased risk of burnout among Lebanese physicians necessitates a combined approach addressing the stressors resulting from both of the pandemic and economic crisis.

\section{Limitations:}

Several limitations should be acknowledged in our study. First, the study had a cross-sectional design which does not allow us to deduce causality. Selection bias is possible due to the snowball technique which limits the generalizability of the findings. The collected data was based on self-reported information which makes it prone to social desirability. Although taking into consideration of some potential confounders in the multivariable models, residual confounding is still possible. Further studies following up on the burnout of Lebanese physicians would be recommended in the future to confirm our results, especially that the economic crisis escalates sharply since December 2020.

\section{Implications for Clinical Practice and Research}

The alarming level of burnout detected among Lebanese physicians represented only the tip of the iceberg of the crisis in Lebanon. Its negative impacts that begin to effervesce with the exodus of some physicians would not be restricted to those healthcare providers but would also affect the patient's quality of care and the healthcare organizations [19]. However, to date, there were no realistic evidence-based interventions and tangible measures that focused on physician burnout in Lebanon. Hence, it is important to address factors identified by our study that potentially contribute to burnout among physicians in order to mitigate the long-term negative consequences. More studies exploring possible interventions based on physicians' preferences and the feasibility of such interventions were recommended.

\section{Conclusion:}

After dealing with more than a year of the stressors of the COVID-19 pandemic combined with an unprecedented economic collapse, Lebanese physicians reached a crisis point and the problem is only getting worse in absence of urgent measures. The huge and serious prevalence of burnout among Lebanese physicians reported by our study called for collaborative efforts from all stakeholders in healthcare to adopt urgent measures and to develop and implement effective remedies for physician burnout.

\section{Abbreviations}

COVID-19: Coronavirus disease 2019

CBI: Copenhagen Burnout Inventory

IFDFW: InCharge Financial Distress/Financial Well-Being

FOC: Fear of COVID-19

HCWs: Health care workers

PPE: Personal Protective Equipment

PB: Personal burnout

WB: Work-related burnout

CB: Client-related burnout

MOPH: Ministry of Public Health

UK: United Kingdom

USA: United States of America

SPSS: Statistical package for social sciences 
C.I: Confidence interval

SD: Standard deviation

a: Cronbach alpha

\section{Declarations}

\section{Author Contributions:}

D.Y. was involved with study conception and design, data collection and analysis, drafting and revising the manuscript.

M.K. and L.A.A. were involved in data collection and revising the article.

J.Y. was involved with study conceptualization and design, drafting and revising the article.

H.S was involved in the study conceptualization and the revision of the manuscript. All authors have read and agreed to the published version of the manuscript.

\section{Funding:}

This research did not receive any specific grant from funding agencies in the public, commercial, or not-for-profit sectors.

\section{Informed Consent Statement:}

Informed consent for participating in the study was obtained digitally through Google Forms from all subjects, and all methods were carried out in accordance with the relevant guidelines and national regulations for the Non-clinical studies. Specifically, at the beginning of the questionnaire, participants were asked whether they agree to participate in the research in order to be included in the study. Participants were also informed that their participation was voluntary and that they had the right to leave at any time without providing any explanation. No incentives were provided to the study participants.

\section{Data Availability Statement:}

After publication, the survey data will be made available on reasonable request to the corresponding author. A proposal with a detailed description of study objectives and a statistical analysis plan will be needed for the assessment of requests. Additional materials might also be required during the process of assessment.

\section{Conflicts of Interest}

The authors declare that they have no competing interests and they have no known competing financial interests or personal relationships that could have appeared to influence the work reported in this paper.

\section{Consent for publication}

Not applicable.

\section{Authors information}

Dalal Youssef, MSc, MPH, RSM, PhD candidate, Ministry of public Health, Preventive medicine department

Janet Youssef, MD, OBGYN, ZHUMC

Linda Abou Abbas, MPH, PhD, Ministry of Public Health, Epidemiological surveillance unit

Malak Kawtharani, MSc, Ministry of public Health, Preventive medicine department

Hamad Hassan, PharmD, PhD, Ministry of Public Health

\section{References}

1. De Hert, S., Burnout in Healthcare Workers: Prevalence, Impact and Preventative Strategies. Local and regional anesthesia, 2020. 13: p. 171-183. 
2. Monsalve-Reyes, C.S., et al., Burnout syndrome and its prevalence in primary care nursing: a systematic review and meta-analysis. BMC Family Practice, 2018. 19(1): p. 59.

3. Organizational Stress: A Review and Critique of Theory, Research, and Applications. 2001: Thousand Oaks, California.

4. Maslach, C., W.B. Schaufeli, and M.P. Leiter, Job Burnout. 2001. 52(1): p. 397-422.

5. Hobfoll, S.E. and J. Freedy, Conservation of resources: A general stress theory applied to burnout, in Professional burnout: Recent developments in theory and research. 1993, Taylor \& Francis: Philadelphia, PA, US. p. 115-133.

6. Keel, P., [Psychological stress caused by work: burnout syndrome]. Soz Praventivmed, 1993. 38 Suppl 2: p. S131-2.

7. Zapf, D., et al., Emotion work and job stressors and their effects on burnout. Psychology \& Health, 2001. 16(5): p. 527-545.

8. Ferguson, S.A., et al., Fatigue in Emergency Services Operations: Assessment of the Optimal Objective and Subjective Measures Using a Simulated Wildfire Deployment. Int J Environ Res Public Health, 2016. 13(2): p. 171.

9. Gundersen, L., Physician burnout. Ann Intern Med, 2001. 135(2): p. 145-8.

10. Ramirez, A.J., et al., Burnout and psychiatric disorder among cancer clinicians. Br J Cancer, 1995. 71(6): p. $1263-9$.

11. Lahoz, M.R. and H.L. Mason, Burnout among pharmacists. Am Pharm, 1990. Ns30(8): p. 28-32.

12. McCarthy, P., Burnout in psychiatric nursing. J Adv Nurs, 1985. 10(4): p. 305-10.

13. Leiter, M.P., P. Harvie, and C. Frizzell, The correspondence of patient satisfaction and nurse burnout. Soc Sci Med, 1998. 47(10): p. 1611-7.

14. Li, L., et al., Stigmatization and shame: consequences of caring for HIV/AIDS patients in China. AIDS Care, 2007. 19(2): p. 258-63.

15. Dyrbye, L.N., et al., Burnout among U.S. medical students, residents, and early career physicians relative to the general U.S. population. Acad Med, 2014. 89(3): p. 443-51.

16. Dyrbye, L.N., et al., Relationship between burnout and professional conduct and attitudes among US medical students. Jama, 2010. 304(11): p. 1173-80.

17. Shanafelt, T.D., Enhancing meaning in work: a prescription for preventing physician burnout and promoting patient-centered care. Jama, 2009. 302(12): p. $1338-40$.

18. Cohen, J.S., et al., The happy docs study: a Canadian Association of Internes and Residents well-being survey examining resident physician health and satisfaction within and outside of residency training in Canada. BMC Res Notes, 2008. 1: p. 105.

19. West, C.P., L.N. Dyrbye, and T.D. Shanafelt, Physician burnout: contributors, consequences and solutions. J Intern Med, 2018. 283(6): p. 516-529.

20. Dyrbye, L.N. and T.D. Shanafelt, Physician burnout: a potential threat to successful health care reform. Jama, 2011. 305(19): p. 2009-10.

21. Pereira, S.M., A.M. Fonseca, and A.S. Carvalho, Burnout in palliative care: a systematic review. Nurs Ethics, 2011. 18(3): p. 317-26.

22. Shanafelt, T.D., et al., The well-being and personal wellness promotion strategies of medical oncologists in the North Central Cancer Treatment Group. Oncology, 2005. 68(1): p. 23-32.

23. Carter, M., et al., Workplace bullying in the UK NHS: a questionnaire and interview study on prevalence, impact and barriers to reporting. BMJ Open, 2013. 3(6): p. e002628.

24. Gazelle, G., J.M. Liebschutz, and H. Riess, Physician burnout: coaching a way out. J Gen Intern Med, 2015. 30(4): p. 508-13.

25. Imo, U.O., Burnout and psychiatric morbidity among doctors in the UK: a systematic literature review of prevalence and associated factors. BJPsych bulletin, 2017. 41(4): p. 197-204.

26. Shanafelt, T.D., et al., Burnout and career satisfaction among American surgeons. Ann Surg, 2009. 250(3): p. 463-71.

27. Shah, K., et al., How Essential Is to Focus on Physician's Health and Burnout in Coronavirus (COVID-19) Pandemic? Cureus, $2020.12(4)$ : p. e7538.

28. Shanafelt, T.D., et al., Burnout and satisfaction with work-life balance among US physicians relative to the general US population. Arch Intern Med, 2012. 172(18): p. 1377-85.

29. Soler, J.K., et al., Burnout in European family doctors: the EGPRN study. Fam Pract, 2008. 25(4): p. 245-65.

30. Sharma, A., et al., Stress and burnout in colorectal and vascular surgical consultants working in the UK National Health Service. Psychooncology, 2008. 17(6): p. 570-6.

31. Aldrees, T.M., et al., Physician well-being: prevalence of burnout and associated risk factors in a tertiary hospital, Riyadh, Saudi Arabia. Annals of Saudi medicine, 2013. 33(5): p. 451-456.

32. Shanafelt, T.D., et al., Burnout and medical errors among American surgeons. Ann Surg, 2010. 251(6): p. 995-1000.

33. Carrau, D. and J.E. Janis, Physician Burnout: Solutions for Individuals and Organizations. Plastic and reconstructive surgery. Global open, 2021. 9(2): p. e3418-e3418.

34. Kowalenko, T., et al., Prospective study of violence against ED workers. The American Journal of Emergency Medicine, 2013. 31(1): p. $197-205$.

35. Sun, T., et al., Workplace violence, psychological stress, sleep quality and subjective health in Chinese doctors: a large cross-sectional study. BMJ Open, 2017. 7(12): p. e017182.

36. Papp, K.K., et al., The effects of sleep loss and fatigue on resident-physicians: a multi-institutional, mixed-method study. Acad Med, 2004. 79(5): p. 394406.

37. Passalacqua, S.A. and C. Segrin, The Effect of Resident Physician Stress, Burnout, and Empathy on Patient-Centered Communication During the Long-Call Shift. Health Communication, 2012. 27(5): p. 449-456.

38. Rosen, I.M., et al., Evolution of sleep quantity, sleep deprivation, mood disturbances, empathy, and burnout among interns. Acad Med, 2006. 81(1): p. 825. 
39. Das, A., et al., A Study to Evaluate Depression and Perceived Stress Among Frontline Indian Doctors Combating the COVID-19 Pandemic. Prim Care Companion CNS Disord, 2020. 22(5).

40. Tam, C.W.C., et al., Severe acute respiratory syndrome (SARS) in Hong Kong in 2003: stress and psychological impact among frontline healthcare workers. Psychological Medicine, 2004. 34(7): p. 1197-1204.

41. Shiao, J.S.-C., et al., Factors Predicting Nurses' Consideration of Leaving their Job During the Sars Outbreak. Nursing Ethics, 2007. 14(1): p. 5-17.

42. Salari, N., et al., The prevalence of sleep disturbances among physicians and nurses facing the COVID-19 patients: a systematic review and meta-analysis. Globalization and Health, 2020. 16(1): p. 92.

43. Naal, H., et al., Evaluating a capacity building program on women's health for displaced community health workers in fragile settings in Lebanon. Human Resources for Health, 2021. 19(1): p. 37.

44. Youssef, J., Economic Overview Lebanon. SSRN Electronic Journal, 2020.

45. El Sayed, M.J., Beirut Ammonium Nitrate Explosion: A Man-Made Disaster in Times of the COVID-19 Pandemic. Disaster Medicine and Public Health Preparedness, 2020: p. 1-5.

46. Cherri, Z., P. Arcos González, and R. Castro Delgado, The Lebanese-Syrian crisis: impact of influx of Syrian refugees to an already weak state. Risk management and healthcare policy, 2016. 9: p. 165-172.

47. Nasr, S. Backdrop to Civil War: The Crisis of Lebanese Capitalism. 1978.

48. Lebanon Economic Monitor, Fall 2019. Lebanon Economic Monitor, Fall 2019.

49. Nassar, C.K. and C.-C. NastacĂ, THE BEIRUT PORT EXPLOSION

50. SOCIAL, URBAN AND ECONOMIC IMPACT. Theoretical and Empirical Researches in Urban Management, 2021. 16(3): p. 42-52.

51. Khan, N., et al., Cross-sectional survey on physician burnout during the COVID-19 pandemic in Vancouver, Canada: the role of gender, ethnicity and sexual orientation. BMJ Open, 2021. 11(5): p. e050380.

52. Jamal, N.E., Lessons Learned from the

53. COVID-19 Pandemic: Physician

54. Safety and Coverage in

55. Lebanon. Arab Reform Initiative, 2021.

56. Shallal, A., et al., Lebanon is losing its front line. Journal of global health, 2021. 11: p. 03052-03052.

57. Shuja, K.H., et al., COVID-19 Pandemic and Impending Global Mental Health Implications. Psychiatr Danub, 2020. 32(1): p. 32-35.

58. Cooper, B., Economic recession and mental health: an overview. Neuropsychiatr, 2011. 25(3): p. 113-7.

59. Akl, E.A., et al., Characteristics of physicians practising in Lebanon: a survey. East Mediterr Health J, 2012. 18(7): p. 712-7.

60. Chong, M.Y., et al., Psychological impact of severe acute respiratory syndrome on health workers in a tertiary hospital. Br J Psychiatry, 2004. 185: $\mathrm{p}$. 12733.

61. Ahorsu, D.K., et al., The Fear of COVID-19 Scale: Development and Initial Validation. International journal of mental health and addiction, 2020 : p. 1-9.

62. Prawitz, A.D., et al., Incharge Financial Distress/Financial Well-Being Scale: Development, Administration, and Score Interpretation. Financial Counseling and Planning, 2006. 17(1): p. 34-50.

63. Tavakol, M. and R. Dennick, Making sense of Cronbach's alpha. International journal of medical education, 2011. 2: p. 53-55.

64. Mishra, P., et al., Descriptive statistics and normality tests for statistical data. Ann Card Anaesth, 2019. 22(1): p. 67-72.

65. Dyrbye, L.N., et al., Relationship between work-home conflicts and burnout among American surgeons: a comparison by sex. Arch Surg, 2011. 146(2): p. 211-7.

66. McMurray, J.E., et al., The work lives of women physicians results from the physician work life study. The SGIM Career Satisfaction Study Group. Journal of general internal medicine, 2000. 15(6): p. 372-380.

67. Koh, D., et al., Risk perception and impact of Severe Acute Respiratory Syndrome (SARS) on work and personal lives of healthcare workers in Singapore: what can we learn? Med Care, 2005. 43(7): p. 676-82.

68. Maunder, R.G., et al., Factors associated with the psychological impact of severe acute respiratory syndrome on nurses and other hospital workers in Toronto. Psychosom Med, 2004. 66(6): p. 938-42.

69. Wu, Y., et al., A Comparison of Burnout Frequency Among Oncology Physicians and Nurses Working on the Frontline and Usual Wards During the COVID19 Epidemic in Wuhan, China. J Pain Symptom Manage, 2020. 60(1): p. e60-e65.

70. Alrawashdeh, H.M., et al., Occupational burnout and job satisfaction among physicians in times of CovID-19 crisis: a convergent parallel mixed-method study. BMC Public Health, 2021. 21(1): p. 811.

71. Romani, M. and K. Ashkar, Burnout among physicians. The Libyan journal of medicine, 2014. 9: p. 23556-23556.

72. Abuzeyad, F., et al., Burnout and Stress Among Emergency Physicians in the Kingdom of Bahrain. 2021.

73. Werdecker, L. and T. Esch, Burnout, satisfaction and happiness among German general practitioners (GPs): A cross-sectional survey on health resources and stressors. PLoS One, 2021. 16(6): p. e0253447.

74. Tomaszek, K. and A. Muchacka-Cymerman, Thinking about My Existence during COVID-19, I Feel Anxiety and Awe-The Mediating Role of Existential Anxiety and Life Satisfaction on the Relationship between PTSD Symptoms and Post-Traumatic Growth. Int J Environ Res Public Health, 2020. 17(19). 
75. McMurray, J.E., et al., The work lives of women physicians results from the physician work life study. The SGIM Career Satisfaction Study Group. J Gen Intern Med, 2000. 15(6): p. 372-80.

76. Morgantini, L.A., et al., Factors Contributing to Healthcare Professional Burnout During the COVID-19 Pandemic: A Rapid Turnaround Global Survey. medRxiv: the preprint server for health sciences, 2020: p. 2020.05.17.20101915.

77. Adam, S., et al., Potential correlates of burnout among general practitioners and residents in Hungary: the significant role of gender, age, dependant care and experience. BMC Fam Pract, 2018. 19(1): p. 193.

78. Baptista, S., et al., Physician Burnout in Primary Care during the COVID-19 Pandemic: A Cross-Sectional Study in Portugal. J Prim Care Community Health, 2021. 12: p. 21501327211008437.

79. Wang, C., et al., Immediate Psychological Responses and Associated Factors during the Initial Stage of the 2019 Coronavirus Disease (COVID-19) Epidemic among the General Population in China. International journal of environmental research and public health, 2020. 17(5): p. 1729.

80. Witte, K. and M. Allen, A meta-analysis of fear appeals: implications for effective public health campaigns. Health Educ Behav, 2000. 27(5): p. 591-615.

81. Beck, A.T., et al., An inventory for measuring clinical anxiety: psychometric properties. J Consult Clin Psychol, 1988. 56(6): p. 893-7.

82. Ahmed, M.Z., et al., Epidemic of COVID-19 in China and associated Psychological Problems. Asian J Psychiatr, 2020. 51: p. 102092.

83. Lund, C., et al., Poverty and common mental disorders in low and middle income countries: A systematic review. Soc Sci Med, 2010. 71(3): p. 517-528.

84. Haw, C., et al., Economic recession and suicidal behaviour: Possible mechanisms and ameliorating factors. Int J Soc Psychiatry, 2015. 61(1): p. 73-81.

85. Ozamiz-Etxebarria, N., et al., Stress, anxiety, and depression levels in the initial stage of the COVID-19 outbreak in a population sample in the northern Spain. Cad Saude Publica, 2020. 36(4): p. e00054020.

86. Stewart, N.H. and V.M. Arora, The Impact of Sleep and Circadian Disorders on Physician Burnout. Chest, 2019. 156(5): p. 1022-1030.

87. Duarte, I., et al., Burnout among Portuguese healthcare workers during the COVID-19 pandemic. BMC Public Health, 2020. 20(1): p. 1885.

88. Žutautienè, R., et al., The Prevalence of Burnout and Its Associations with Psychosocial Work Environment among Kaunas Region (Lithuania) Hospitals' Physicians. International journal of environmental research and public health, 2020. 17(10): p. 3739.

89. Dinibutun, S.R., Factors Associated with Burnout Among Physicians: An Evaluation During a Period of COVID-19 Pandemic. Journal of healthcare leadership, 2020. 12: p. 85-94.

90. Salameh, P., et al., Mental Health Outcomes of the COVID-19 Pandemic and a Collapsing Economy: Perspectives from a Developing Country. Psychiatry research, 2020. 294: p. 113520-113520.

\section{Tables}


Table 1: Socio-demographics characteristics of surveyed physicians $(\mathrm{N}=398)$

n $\%$

\begin{tabular}{lll} 
Gender & & \\
\hline Male & 210 & $52.80 \%$ \\
\hline Female & 188 & $47.20 \%$ \\
\hline
\end{tabular}

Age (years)

\begin{tabular}{lll} 
Less than $40 \mathrm{y}$ & 143 & $35.90 \%$ \\
\hline $40-49 \mathrm{y}$ & 172 & $43.20 \%$ \\
\hline $50 \mathrm{y}$ & 83 & $20.81 \%$
\end{tabular}

Marital status

\begin{tabular}{lll}
\hline Single & 152 & $38.20 \%$ \\
\hline Married/Engaged & 239 & $60.10 \%$ \\
\hline Other (Divorced or Widowed) & 7 & $1.80 \%$ \\
\hline Residence & & \\
\hline North \& Akkar & 66 & $16.60 \%$ \\
\hline Mount Lebanon & 138 & $34.70 \%$ \\
\hline Beirut & 105 & $26.40 \%$ \\
\hline South \& Nabatyeh & 45 & $11.30 \%$ \\
\hline Bekaa \& Baalbeck-Hermel & 42 & $11.00 \%$ \\
\hline Working experience & & \\
\hline Less than 10 years & 120 & $30.15 \%$ \\
\hline 10 years and more & 278 & $69.85 \%$ \\
\hline
\end{tabular}

Previous experience in Outbreak/Pandemic/Emergency

\begin{tabular}{lll}
\hline No & 103 & $25.88 \%$ \\
\hline Yes & 295 & $74.12 \%$ \\
\hline Health facility type & & \\
\hline Public & 133 & $33.40 \%$ \\
\hline Private & 265 & $66.60 \%$ \\
\hline Presence of child at home & & \\
\hline No & 208 & $52.30 \%$ \\
\hline Yes & 190 & $47.70 \%$ \\
\hline Presence of elderly people at home & & \\
\hline No & 211 & $47.00 \%$ \\
\hline Yes & 187 & $53.00 \%$ \\
\hline Living with family member with comorbidities & & \\
\hline No & 184 & $46.20 \%$ \\
\hline Yes & 214 & $53.80 \%$ \\
\hline Working in frontline in the response to CoVID-19 & & \\
\hline No & 151 & $37.90 \%$ \\
\hline Yes & 207 & $62.10 \%$ \\
\hline Following up or caring of CoVID-19 case & & \\
\hline No & 191 & $48.10 \%$ \\
\hline Yes & & $51.90 \%$ \\
\hline Perse & & \\
\hline & & \\
\hline
\end{tabular}

Personal history of COVID-19 diagnosis 


$\begin{array}{lll}\text { No } & 337 & 84.70 \% \\ \text { Yes } & 61 & 15.30 \%\end{array}$

Family member/friend or colleague ever diagnosed with COVID-19

\begin{tabular}{lll} 
No & 222 & $55.80 \%$ \\
\hline Yes & 176 & $44.20 \%$
\end{tabular}

Colleague ever diagnosed with COVID-19

$\begin{array}{lll}\text { No } & 39 & 9.80 \% \\ \text { Yes } & 359 & 90.20 \%\end{array}$

Note: n: Frequency, \% Percentage, 
Table 2: Descriptive statistics of the scales used in the study

Scale items

Mean

IFDFW InCharge Financial Distress/Financial Well-Being Scale $(\alpha=0.85)$

$22.85 \quad 7.64$

IFDFW1 What do you feel is the level of your financial stress today?

$2.98 \quad 1.48$

IFDFW2 How satisfied you are with your present financial situation.

$2.78 \quad 1.26$

IFDFW3 How do you feel about your current financial situation?

$2.81 \quad 1.41$

IFDFW4 How often do you worry about being able to meet normal monthly living expenses?

$2.94 \quad 1.47$

IFDFW5 How confident are you that you could find the money to pay for a financial emergency

$3.16 \quad 1.58$

IFDFW6 How often do you want to do something (eating outside, vacation, watching movie, practicing a hobby....) and don't go because you can't afford to?

IFDFW7 How frequently do you find yourself just getting by financially and living paycheck to paycheck?

2.490 .94

IFDFW8 How stressed do you feel about your personal finances in general?

$2.69 \quad 1.22$

FOC

Fear of COVID19 $(\alpha=0.769)$

$3.00 \quad 1.48$

Fear1 I am most afraid of getting infected by COVID-19

$17.88 \quad 1.4$

Fear2 It makes me uncomfortable to think about Corona

$3.82 \quad 0.40$

$2.03 \quad 0.33$

Fear3 I am afraid of losing my life because of Corona

$2.31 \quad 0.69$

Fear4 When I watch news and stories about Corona on social media, I become nervous or anxious

3.690 .49

Fear5 I cannot sleep because l'm worrying about getting Corona

$2.04 \quad 0.27$

Fear6 My heart races or palpitates when I think about getting Corona

$2.05 \quad 0.25$

Fear7 My hands become clammy when I think about Corona

$1.97 \quad 0.17$

TPS Threat perception scale $(\alpha=0.703)$

$35.53 \quad 2.88$

Threat1 My job puts me at great risk

$4.02 \quad 0.63$

Threat2 I feel more stress at work

$4.00 \quad 0.47$

Threat3 I have little control over whether I get infected or not

$3.61 \quad 0.76$

Threat4 I have little chance of survival if I were to get SARS

$2.13 \quad 0.46$

Threat5 I think of resigning because of SARS

$2.17 \quad 0.45$

Threat6 I am afraid I will pass SARS to others

$3.93 \quad 0.40$

Threat7 My family and friends are worried they get infected through me

$4.07 \quad 0.32$

Threat8 People avoid my family because of my work

3.830 .98

Threat9 I am afraid of falling ill with SARS

$4.04 \quad 0.50$

ALtru1 I accept the risk of caring for SARS patient ${ }^{R}$

$3.74 \quad 0.55$

CBI Copenhagen burnout inventory scale $(a=0.879)$

$65.34 \quad 17.39$

Personal burnout ( $a=0.921)$

$64.80 \quad 17.32$

PB1 How often do you feel tired?

$63.57 \quad 17.87$

PB2 How often are you physically exhausted?

$63.94 \quad 17.84$

PB3 How often are you emotionally exhausted?

$65.01 \quad 17.72$

PB4 How often do you think: "I can't take it anymore"?

$65.45 \quad 15.47$

PB5 How often do you feel worn out?

$65.52 \quad 17.91$

PB6 How often do you feel weak and susceptible to illness?

$65.33 \quad 17.67$

Work-related burnout $(a=0.832)$

$71.50 \quad 16.33$

WB1 Is your work emotionally exhausting?

$72.49 \quad 16.36$

WB2 Do you feel burnt out because of your work?

$70.85 \quad 14.03$

8WB3 Does your work frustrate you?

$71.80 \quad 16.86$

WB4 Do you feel worn out at the end of the working day?

$71.83 \quad 16.29$

Page $14 / 23$ 


\begin{tabular}{|c|c|c|c|}
\hline WB5 & Are you exhausted in the morning at the thought of another day at work? & 71.04 & 15.32 \\
\hline WB6 & Do you feel that every working hour is tiring for you? & 71.55 & 14.49 \\
\hline \multirow[t]{2}{*}{ WB7 } & Do you have enough energy for family and friends during leisure time? $\mathbf{R}$ & 70.98 & 15.76 \\
\hline & Client burnout $(a=0.874)$ & 58.70 & 16.14 \\
\hline CB1 & Do you find it hard to work with clients? & 56.91 & 23.33 \\
\hline CB2 & Do you find it frustrating to work with clients? & 57.22 & 24.00 \\
\hline CB3 & Does it drain your energy to work with clients? & 55.65 & 19.18 \\
\hline CB4 & Do you feel that you give more than you get back when you work with clients? & 56.09 & 22.42 \\
\hline CB5 & Are you tired of working with clients? & 71.23 & 20.58 \\
\hline CB6 & Do you sometimes wonder how long you will be able to continue working with clients? & 55.09 & 19.30 \\
\hline
\end{tabular}

M:mean, SD:standard deviation, R: reversed coding 
Table 3: Association between socio-demographic characteristics and $\mathrm{CBI}$ subscales ( $\mathrm{N}=398$ )

\begin{tabular}{|c|c|c|c|c|c|c|c|c|c|c|c|}
\hline & \multicolumn{4}{|c|}{ Overall CBI } & \multicolumn{3}{|c|}{ Personal burnout } & \multicolumn{3}{|c|}{ Work-related burnout } & \multirow{2}{*}{$\frac{\text { Clie }}{\mathrm{M \epsilon}}$} \\
\hline & $\begin{array}{l}\mathrm{n}(\%) \\
\mathrm{N}=398\end{array}$ & Mean (SD) & $\begin{array}{l}\mathrm{P} \text { - } \\
\text { value }\end{array}$ & $\begin{array}{l}\text { Eta } \\
\text { Squared }\end{array}$ & Mean (SD) & $\begin{array}{l}\mathrm{P}- \\
\text { value }\end{array}$ & $\begin{array}{l}\text { Eta } \\
\text { squared }\end{array}$ & Mean (SD) & $\begin{array}{l}\mathrm{P} \text { - } \\
\text { value }\end{array}$ & $\begin{array}{l}\text { Eta } \\
\text { squared }\end{array}$ & \\
\hline Gender & & & 0.035 & 0.018 & & 0.039 & 0.011 & & 0.048 & 0.005 & \\
\hline Male & $\begin{array}{l}210 \\
(52.8 \%)\end{array}$ & 64.01(10.96) & & & 63.82(16.55) & & & 70.86(15.33) & & & 56.1 \\
\hline Female & $188(47.2 \%)$ & 65.64(9.37) & & & 65.78(14.54) & & & $72.21(13.28)$ & & & $60 .:$ \\
\hline Age (years) & & & 0.048 & 0.12 & & 0.022 & 0.09 & & 0.189 & 0.001 & \\
\hline Less than $40 \mathrm{y}$ & $143(35.9 \%)$ & $66.56(11.39$ & Ref & & 67.37(15.66) & Ref & & 72.16(15.79) & & & 59.: \\
\hline$\geq 40 y$ & $255(64.1 \%)$ & 64.04(9.71) & 0.032 & & $62.99(15.84)$ & 0.007 & & 71.25(13.29) & & & 56.1 \\
\hline Marital status & & & 0.001 & 0.139 & & 0.025 & 0.116 & & 0.045 & 0.076 & \\
\hline Single/Divorced & 159(39.9\%) & 66.83(10.72) & & & $66.52(14.84)$ & & & 72.38(15.22) & & & 61.4 \\
\hline Married/Engaged & $239(60.1 \%)$ & 63.12(9.01) & & & 61.31(16.79) & & & 68.87(15.11) & & & 59.1 \\
\hline Residence & & & 0.581 & 0.003 & & 0.635 & 0.004 & & 0.377 & 0.005 & \\
\hline North/Akkar & $66(16.6 \%)$ & $66.01(10.06)$ & & & $66.01(12.08)$ & & & 71.11(14.97) & & & 59. \\
\hline Mount Lebanon & 138(34.7\%) & $64.23(10.38)$ & & & $67.23(16.53)$ & & & 70.62(13.89) & & & 53. \\
\hline Beirut & $105(26.4 \%)$ & 65.63(11.05) & & & $64.37(16.66)$ & & & $71.89(15.11)$ & & & 59.1 \\
\hline South/Nabatyeh & $45(11.3 \%)$ & 64.18(7.61) & & & 65.93(13.91) & & & 69.21(12.77) & & & $56 . !$ \\
\hline Great Bekaa & $42(11 \%)$ & $64.98(8.01)$ & & & $63.63(12.25)$ & & & 72.48(11.67) & & & $57 . !$ \\
\hline \multicolumn{3}{|c|}{ Presence of dependent children at home } & 0.047 & 0.01 & & 0.013 & 0.121 & & 0.022 & 0.012 & \\
\hline No & $208(52.3 \%)$ & $64.38(10.23)$ & & & $62.62(15.47)$ & & & $70.75(15.03)$ & Ref & & 57.1 \\
\hline Yes & $190(47.7 \%)$ & $66.40(10.18)$ & & & $67.19(15.46)$ & & & 72.18(13.79) & & & $60 . !$ \\
\hline \multicolumn{3}{|c|}{ Presence of elderly at home } & 0.014 & 0.011 & & 0.031 & 0.014 & & 0.047 & 0.009 & \\
\hline No & $211(47 \%)$ & $63.18(9.74)$ & & & $63.62(14.47)$ & & & $70.75(15.03)$ & Ref & & $58 .:$ \\
\hline Yes & $187(53 \%)$ & $68.61(10.98)$ & & & $67.89(13.46)$ & & & 72.18(13.79) & & & 60. \\
\hline \multicolumn{3}{|c|}{ Family member with comorbidities } & 0.045 & 0.018 & & 0.042 & 0.01 & & 0.038 & 0.01 & \\
\hline No & $184(46.2 \%)$ & 63.98(10.23) & & & $63.62(15.08)$ & & & 70.75(15.03) & Ref & & 56.1 \\
\hline Yes & $214(53.8 \%)$ & $67.10(11.03)$ & & & $66.84(14.86)$ & & & 72.18(13.79) & & & $60 . !$ \\
\hline
\end{tabular}

$\mathrm{N}$ : frequency, \%: Percentage, SD: standard deviation, Eta sq.: Eta squared, the mean was unstandardized, Great bekaa included Bekaa and BaalbeckHermel pr 
Table 4: Association between economic factors and $\mathrm{CBI}$ subscales $(\mathrm{N}=398)$

\begin{tabular}{|c|c|c|c|c|c|c|c|c|c|c|c|c|}
\hline & & Overall CBI & & & Personal burnc & & & Work-related b & Jrnout & & Client-related b & \\
\hline & $\begin{array}{l}n(\%), \\
N=398\end{array}$ & Mean (SD) & $\begin{array}{l}\mathrm{P} \text { - } \\
\text { value }\end{array}$ & $\begin{array}{l}\text { Eta } \\
\text { sq. }\end{array}$ & Mean (SD) & $\begin{array}{l}\mathrm{P} \text { - } \\
\text { value }\end{array}$ & $\begin{array}{l}\text { Eta } \\
\text { sq. }\end{array}$ & Mean (SD) & $\begin{array}{l}\mathrm{P} \text { - } \\
\text { value }\end{array}$ & $\begin{array}{l}\text { Eta } \\
\text { sq. }\end{array}$ & Mean (SD) & $\begin{array}{l}\mathbf{P} \\
\mathbf{V}\end{array}$ \\
\hline $\begin{array}{l}\text { Socio-econom } \\
\text { COVID-19/ }\end{array}$ & $\begin{array}{l}\text { c status after } \\
\text { conomic crisis* }\end{array}$ & & $<0.001$ & 0.149 & & $<0.001$ & 0.121 & & $<0.001$ & 0.152 & & 0 \\
\hline Rich & $3(0.7 \%)$ & $59.19(11.23)$ & Ref & & $58.25(15.33)$ & Ref & & 67.31(16.75) & Ref & & 57.01(15.76) & $\mathrm{R}$ \\
\hline Middle & $125(31.4 \%)$ & $64.12(9.75)$ & 0.008 & & 64.67(16.76) & & & 71.83(18.15) & & & $58.22(16.32)$ & 0 \\
\hline $\begin{array}{l}\text { Middle to } \\
\text { low }\end{array}$ & $273(43.5 \%)$ & 72.71(10.34) & $<0.001$ & & 71.48(17.32) & & & $75.36(15.23)$ & & & $60.87(16.03)$ & 0 \\
\hline $\begin{array}{l}\text { Current } \\
\text { income }\end{array}$ & & & $<0.001$ & 0.046 & & 0.035 & 0.081 & & 0.006 & 0.076 & & $<1$ \\
\hline $\begin{array}{l}<2 \text { Million } \\
\text { L.L }\end{array}$ & $68(17.1 \%)$ & $67.87(12.05)$ & Ref & & $66.44(17.22)$ & Ref & & 73.678(16.5) & Ref & & 64.04(19.17) & $\mathrm{R}$ \\
\hline $\begin{array}{l}\text { 2-4 Million } \\
\text { L.L }\end{array}$ & $172(44.2 \%)$ & $65.49(11.4)$ & 0.087 & & $63.39(14.85)$ & 0.046 & & 73.37(13.45) & 0.543 & & $56.37(20.26)$ & 0 \\
\hline $\begin{array}{l}>4 \text { Million } \\
\text { L.L }\end{array}$ & 154(38.7\%) & $63.07(7.09)$ & $<0.001$ & & 61.98(15.82) & 0.021 & & 68.91(11.54) & 0.001 & & $54.92(16.55)$ & $<1$ \\
\hline $\begin{array}{l}\text { Pandemic imp } \\
\text { income }\end{array}$ & act on & & 0.046 & 0.082 & & 0.033 & 0.082 & & 0.043 & 0.051 & & $<$ \\
\hline Minor & $60(15.1 \%)$ & $63.11(9.67)$ & Ref & & $62.92(16.06)$ & Ref & & $68.41(14.25)$ & Ref & & $56.96(16.32)$ & $\mathrm{R}$ \\
\hline Moderate & $199(50 \%)$ & $64.85(9.68)$ & 0.154 & & $65.71(16.01)$ & 0.048 & & $72.44(14.67)$ & 0.049 & & $58.12(14.97)$ & 0 \\
\hline Major & $139(34.9 \%)$ & $68.24(10.83)$ & 0.009 & & $66.94(12.4)$ & 0.031 & & $74.50(13.99)$ & 0.018 & & $60.53(18.17)$ & $<1$ \\
\hline $\begin{array}{l}\text { Economic cris } \\
\text { your income }\end{array}$ & s impact on & & $<0.001$ & 0.132 & & 0.038 & 0.026 & & 0.023 & 0.032 & & 0 \\
\hline Minor & $3(0.7 \%)$ & $58.47(10.06)$ & Ref & & 61.13(15.83) & Ref & & $69.25(14.76)$ & Ref & & $56.98(14.76)$ & $\mathrm{R}$ \\
\hline Moderate & $57(14.3 \%)$ & $64.72(11.28)$ & $<0.001$ & & $64.67(16.04)$ & 0.256 & & 70.05(13.18) & 0.276 & & $58.62(15.23)$ & \\
\hline Major & $338(84.9 \%)$ & 73.01(10.81) & $<0.001$ & & $68.03(16.45)$ & 0.009 & & $75.12(14.21)$ & 0.003 & & $60.31(15.76)$ & \\
\hline $\begin{array}{l}\text { Health } \\
\text { coverage }\end{array}$ & & & 0.044 & 0.018 & & 0.362 & 0.002 & & 0.168 & 0.000 & & 0 \\
\hline Public & $23(5.7 \%)$ & $64.81(9.41)$ & & & $64.38(15.51)$ & & & $70.62(14.11)$ & & & $58.44(15.45)$ & \\
\hline $\begin{array}{l}\text { Private } \\
\text { (insurance, } \\
\text { syndicates..) }\end{array}$ & $375(94.3 \%)$ & 67.11(12.03) & & & $65.66(16.07)$ & & & $74.26(14.72)$ & & & $60.22(20.34)$ & \\
\hline Scale & Mean (SD) & Correlation (r) & & alue & Correlation (r) & & alue & Correlation (r) & & alue & Correlation (r) & \\
\hline IFDWF scale & $2.86(1.43)$ & -0.23 & $p<0.01$ & & -0.278 & $<0.01$ & & -0.212 & $<0.01$ & & -0.17 & $<1$ \\
\hline
\end{tabular}

$\mathrm{N}$ : frequency, \%: Percentage, SD: standard deviation, Eta sq.: Eta squared, the mean was unstandardized 
Table 5: Work characteristics and $\mathrm{CBI}$ subscales $(\mathrm{N}=398)$

Overall CBI

Personal burnout

Work-related burnout

Client-related bumout

\begin{tabular}{|c|c|c|c|c|c|c|c|c|c|c|c|}
\hline $\begin{array}{l}N(\%) \\
N=398\end{array}$ & Mean (SD) & $\begin{array}{l}\mathrm{P} \text { - } \\
\text { value }\end{array}$ & $\begin{array}{l}\text { Eta } \\
\text { squ }\end{array}$ & $\begin{array}{l}\text { Mean } \\
\text { (SD) }\end{array}$ & $\begin{array}{l}P \text { - } \\
\text { value }\end{array}$ & $\begin{array}{l}\text { Eta } \\
\text { squ }\end{array}$ & Mean (SD) & $\begin{array}{l}\mathrm{P} \text { - } \\
\text { value }\end{array}$ & $\begin{array}{l}\text { Eta } \\
\text { squ }\end{array}$ & Mean (SD) & $\begin{array}{l}\mathrm{P} \text { - } \\
\text { value }\end{array}$ \\
\hline y type & & & & & 0.035 & 0.011 & & 0.012 & 0.029 & & 0.03 \\
\hline
\end{tabular}

\begin{tabular}{|c|c|c|c|c|c|c|c|c|c|c|c|c|}
\hline \multicolumn{6}{|c|}{ Health facility type } & \multirow[t]{2}{*}{0.035} & \multirow[t]{2}{*}{0.011} & & \multirow[t]{2}{*}{0.012} & \multirow[t]{2}{*}{0.029} & & \multirow[t]{2}{*}{0.03} \\
\hline Private & $\begin{array}{l}265 \\
(66.6 \%)\end{array}$ & $62.5(10.36)$ & & & $62.98(12.68)$ & & & 69.11(13.34) & & & $56.64(16.25)$ & \\
\hline Public & $133(33.4 \%)$ & $68.1(10.06)$ & & & $65.03(11.76)$ & & & $73.46(14.22)$ & & & $60.34(16.8)$ & \\
\hline \multicolumn{2}{|c|}{ Location of the hospital } & & 0.143 & 0.001 & & 0.511 & 0.002 & & 0.018 & 0.009 & & 0.308 \\
\hline Rural & $109(27.4 \%)$ & 64.31(11.22) & & & $63.54(14.71)$ & & & 69.08(15.18) & & & $58.54(17.05)$ & \\
\hline Urban & $289(72.6 \%)$ & $66.52(10.83)$ & & & $65.21(15.12)$ & & & 73.8(14.27) & & & $58.82(16.94)$ & \\
\hline \multicolumn{2}{|c|}{ Working experience } & & 0.003 & 0.010 & & 0.043 & 0.019 & & 0.028 & 0.017 & & 0.64 \\
\hline $\begin{array}{l}\text { Less than } \\
10 \text { years }\end{array}$ & $120(30.1 \%)$ & $68.25(11.83)$ & & & 67.99(15.13) & & & 73.15(14.22) & & & & \\
\hline $\begin{array}{l}10 \text { years } \\
\text { and more }\end{array}$ & $278(69.8 \%)$ & $62.64(11.47)$ & & & 63.02(14.73) & & & 68.13(13.89) & & & $58.48(16.44)$ & \\
\hline \multicolumn{3}{|c|}{$\begin{array}{l}\text { Previous experience in } \\
\text { Outbreak/Pandemic/Emergency }\end{array}$} & 0.048 & 0.009 & & 0.043 & 0.018 & & 0.031 & 0.008 & & 0.038 \\
\hline No & $103(25.8 \%)$ & $65.81(10.46)$ & & & $65.39(15.83)$ & & & $73.59(13.25)$ & & & $59.25(17.29)$ & \\
\hline Yes & $295(74.1 \%)$ & $62.74(8.52)$ & & & $61.54(14.02)$ & & & $67.64(11.68)$ & & & $55.66(14.82)$ & \\
\hline \multicolumn{2}{|l|}{$\begin{array}{l}\text { Sleeping } \\
\text { hours }\end{array}$} & & $<0.001$ & 0.022 & & 0.002 & 0.031 & & 0.018 & 0.000 & & 0.339 \\
\hline $\begin{array}{l}\text { Less than } \\
6 \text { hours }\end{array}$ & $210(57.7 \%)$ & 69.03(10.35) & & & $67.53(15.38)$ & & & $67.48(12.27)$ & & & $57.88(17.11)$ & \\
\hline $\begin{array}{l}\text { More } \\
\text { than } 6 \\
\text { hours }\end{array}$ & $168(42.2 \%)$ & $61.18(11.22)$ & & & $62.02(13.17)$ & & & 74.01(14.31) & & & $58.98(16.89)$ & \\
\hline \multicolumn{2}{|l|}{$\begin{array}{l}\text { Extensive } \\
\text { working } \\
\text { hours }\end{array}$} & & 0.011 & 0.017 & & 0.876 & 0.000 & & 0.022 & 0.012 & & 0.43 \\
\hline No & $99(24.8 \%)$ & $62.56(9.08)$ & & & $64.54(13.51)$ & & & 70.01(14.34) & & & $57.03(16.25)$ & \\
\hline Yes & $299(72.3 \%)$ & $66.53(10.86)$ & & & $64.34(14.72)$ & & & 72.18(15.12) & & & $60.12(16.8)$ & \\
\hline \multicolumn{3}{|c|}{ Economic crisis impact on your work } & $<0.001$ & 0.053 & & 0.038 & 0.026 & & 0.023 & 0.032 & & 0.234 \\
\hline Minor & $13(0.7 \%)$ & $58.47(10.06)$ & Ref & & 61.13(15.83) & Ref & & $69.25(14.76)$ & Ref & & $56.98(14.76)$ & \\
\hline Moderate & $97(14.3 \%)$ & $64.72(11.28)$ & $<0.001$ & & $64.67(16.04)$ & 0.256 & & 70.05(13.18) & 0.276 & & $58.62(15.23)$ & \\
\hline Major & $288(84.9 \%)$ & 73.01(10.81) & $<0.001$ & & $68.03(16.45)$ & 0.009 & & $75.12(14.21)$ & 0.003 & & $60.31(15.76)$ & \\
\hline
\end{tabular}

$\mathrm{N}$ : frequency, \%: Percentage, SD: standard deviation, Eta sq.: Eta squared, the mean was unstandardized 
Table 6: Association between COVID-19 exposure, health characteristics, COVID-19 impact and CBI subscales ( $N=398$ )

\begin{tabular}{|c|c|c|c|c|c|c|c|c|c|c|c|c|}
\hline & \multirow{2}{*}{$n(\%)}$, & \multicolumn{3}{|l|}{ Overall CBI } & \multicolumn{3}{|c|}{ Personal burnout } & \multicolumn{3}{|c|}{ Work-related burnout } & \multicolumn{2}{|c|}{ Client-related bur } \\
\hline & & Mean (SD) & $\begin{array}{l}\mathrm{P} \text { - } \\
\text { value }\end{array}$ & $\begin{array}{l}\text { Eta } \\
\text { squ. }\end{array}$ & Mean (SD) & $\begin{array}{l}\mathrm{P} \text { - } \\
\text { value }\end{array}$ & $\begin{array}{l}\text { Eta } \\
\text { squ. }\end{array}$ & Mean (SD) & $\begin{array}{l}\mathrm{P} \text { - } \\
\text { value }\end{array}$ & $\begin{array}{l}\text { Eta } \\
\text { squ. }\end{array}$ & Mean (SD) & i \\
\hline Health status & & & 0.002 & 0.021 & & 0.035 & 0.011 & & 0.012 & 0.029 & & c \\
\hline $\begin{array}{l}\text { Fair and } \\
\text { Below }\end{array}$ & $70(17.6 \%)$ & 68.1(10.36) & & & $66.28(14.68)$ & & & $\begin{array}{l}74.16 \\
(13.88)\end{array}$ & & & $\begin{array}{l}59.34 \\
(16.25)\end{array}$ & \\
\hline $\begin{array}{l}\text { Good and } \\
\text { above }\end{array}$ & $328(82.4 \%)$ & $62.5(10.67)$ & & & $\begin{array}{l}63.11 \\
(14.76)\end{array}$ & & & $\begin{array}{l}68.31 \\
(12.94)\end{array}$ & & & $57.64(16.8)$ & \\
\hline $\begin{array}{l}\text { Working in } \\
\text { frontline }\end{array}$ & & & 0.038 & 0.016 & & 0.04 & 0.011 & & 0.032 & 0.009 & & c \\
\hline No & $151(37.9 \%)$ & 63.5(10.36) & & & $62.9(15.48)$ & & & 69.41(14.63) & & & $56.64(17.25)$ & \\
\hline Yes & $247(61.1 \%)$ & $67.1(10.06)$ & & & $66.28(15.76)$ & & & $73.16(14.22)$ & & & $60.34(16.8)$ & \\
\hline $\begin{array}{l}\text { Following up } \\
\text { or caring of } \\
\text { COVID-19 } \\
\text { case }\end{array}$ & & & 0.325 & 0.001 & & 0.421 & 0.003 & & 0.018 & 0.022 & & $c$ \\
\hline No & $191(48.1 \%)$ & $64.17(10.39)$ & & & 65.54(14.71) & & & 70.08(15.18) & & & $57.54(17.05)$ & \\
\hline Yes & $207(51.9 \%)$ & 66.32(10.14) & & & $64.21(16.29)$ & & & 72.8(13.77) & & & $59.82(16.94)$ & \\
\hline $\begin{array}{l}\text { Tested for } \\
\text { COVID-19 }\end{array}$ & & & 0.794 & 0.000 & & 0.053 & 0.009 & & 0.098 & 0.007 & & $c$ \\
\hline No & $91(22.9 \%)$ & $65.64(10.47)$ & & & $63.97(15.63)$ & & & 69.31(14.83) & & & $58.48(16.44)$ & \\
\hline Yes & $307(77.1 \%)$ & $65.25(10.18)$ & & & $67.58(15.13)$ & & & $72.15(14.22)$ & & & $59.43(18.71)$ & \\
\hline $\begin{array}{l}\text { History of } \\
\text { COVID-19 } \\
\text { diagnosis }\end{array}$ & & & 0.031 & 0.012 & & 0.043 & 0.018 & & 0.231 & 0.002 & & c \\
\hline No & $337(84.7 \%)$ & $65.81(10.46)$ & & & $65.39(15.83)$ & & & 71.79(14.65) & & & $59.25(17.29)$ & \\
\hline Yes & $61(15.3 \%)$ & 62.74(8.52) & & & 61.54(14.02) & & & 69.84(12.88) & & & $55.66(14.82)$ & \\
\hline $\begin{array}{l}\text { Family } \\
\text { member } \\
\text { diagnosed as } \\
\text { COVID-19 }\end{array}$ & & & 0.549 & 0.001 & & 0.762 & 0.000 & & 0.989 & 0.000 & & $c$ \\
\hline No & $222(55.8 \%)$ & $64.99(10.49)$ & & & $64.53(15.58)$ & & & $71.48(14.54)$ & & & $57.88(17.11)$ & \\
\hline Yes & $176(44.2 \%)$ & $65.62(10.05)$ & & & $65.02(15.67)$ & & & 71.51(14.31) & & & $59.34(16.87)$ & \\
\hline $\begin{array}{l}\text { Colleague } \\
\text { ever } \\
\text { diagnosed } \\
\text { with COVID- } \\
19\end{array}$ & & & 0.245 & 0.004 & & 0.39 & 0.003 & & 0.004 & 0.048 & & $c$ \\
\hline No & $39(9.8 \%)$ & 63.56(8.56) & & & 64.33(15.44) & & & $65.29(14.33)$ & & & $55.98(14.61)$ & \\
\hline Yes & $359(90.2 \%)$ & $65.53(10.41)$ & & & 69.12(16.68) & & & 71.17(14.26) & & & $58.99(17.21)$ & \\
\hline $\begin{array}{l}\text { Pandemic } \\
\text { impact on } \\
\text { daily life }\end{array}$ & & & 0.021 & 0.013 & & 0.038 & 0.026 & & 0.009 & 0.028 & & C \\
\hline Minor & $42(10.5 \%)$ & 63.992(8.76) & Ref & & $63.29(15.42)$ & Ref & & $66.42(15.49)$ & Ref & & $56.59(13.92)$ & $\mathrm{F}$ \\
\hline Moderate & $96(24.2 \%)$ & 64.17(9.38) & 0.213 & & $65.27(15.48)$ & $0 . .079$ & & $68.72(13.46)$ & 0.213 & & $59.37(18.21)$ & C \\
\hline Major & $260(65.3 \%)$ & 66.96(10.86) & 0.006 & & 66.98(16.10) & 0.002 & & 73.06(14.54) & $<0.001$ & & 63.61(15.71) & $<$ \\
\hline $\begin{array}{l}\text { Pandemic } \\
\text { impact on } \\
\text { social } \\
\text { relationship }\end{array}$ & & & 0.176 & 0.002 & & 0.003 & 0.031 & & 0.321 & 0.000 & & $c$ \\
\hline Minor & $31(7.8 \%)$ & 64.17(9.38) & & & 61.33(15.76) & & & $70.23(12.67)$ & & & 57.33(17.05) & \\
\hline Moderate & $185(46.5 \%)$ & $65.32(9.56)$ & & & $65.78(15.02)$ & & & 71.97(14.13) & & & $58.71(16.94)$ & \\
\hline Major & $182(45.7 \%)$ & $66.23(10.15)$ & & & 69.45(14.98) & & & 72.33(14.46) & & & $59.82(16.13)$ & \\
\hline $\begin{array}{l}\text { Pandemic } \\
\text { impact on }\end{array}$ & & & 0.115 & 0.025 & & 0.412 & 0.003 & & 0.298 & 0.002 & & c \\
\hline
\end{tabular}




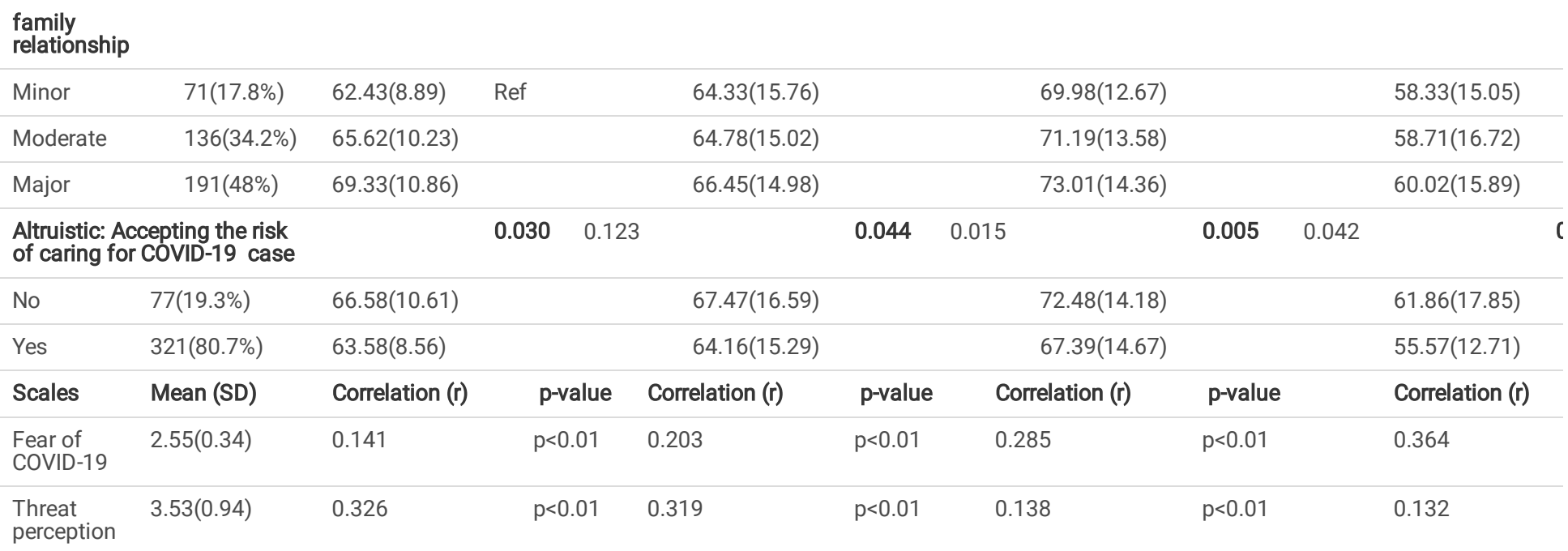

$\mathrm{N}$ : frequency, \%: Percentage, SD: standard deviation, Eta sq.: Eta squared, the mean was unstandardized 
Table 7: Multivariable analyses: Correlates of $\mathrm{CBI}$ and its subscales

$\begin{array}{ll}\text { Model } & \text { Standardized Coefficients } \\ \text { Beta }\end{array}$

\section{Correlates of the overall CB}

Female gender

Age $(\geq 40$ vs $<40$ y)

Marital status (married versus single/divorced

Specialty (other specialties vs ID/internal medicine)

Hospital type (private vs public)

Threat perception scale

IFDFW scale

Sleeping hours ( $\leq 6$ hours vs $>66$ hours)

Low income

Health status (good vs poor)

Child at home

Family member with chronic disease

Working in the frontline

Diagnosed as COVID19 case

Previous experience of working in outbreaks

Work experience (small vs large)

Fear of COVID-19

Altruistic(yes vs no)

Extensive working hours

Sleeping hours (less than 6 hours vs more than 6 hours)

Correlates of the Personal burnout

Age $(>40 \mathrm{y})$

Marital status (Single/divorced vs Married)

Gender (Female)

Health condition (Good vs bad)

Elderly at home

Presence of child at home

Family member with comorbidities

Presence of elderly at home

Threat perception scale

Altruistic

Extensive working hours

Low income

Fear of COVID-19

IFDFW scale

Sleeping hours

\section{Correlates of Work-related burnout}

Age ( $>40$ y vs less than $40 y$ )

Marital status (Single/divorced vs Married)

0.202

$-0.167$

$-0.496$

$-0.876$

$-0.130$

0.478

$-0.222$

0.169

0.318

$-0.123$

0.397

0.104

0.318

$-0.185$

$-0.289$

0.092

0.311

$-0.167$

0.131

0.299 P-
value

Confidence interva

Lower Upper

bound Bound

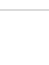

022

0.022

0.062

0.001

0.062

$-2.377$

1.038

0.010

$-2.466$

$-0.132$

0.048

$-2.321$

$-0.332$

$<0.001 \quad-3.272$

$-0.514$

$-1.091$

0.001

0.187

0.742

$0.044 \quad-1.934$

$-0.048$

$0.038 \quad 0.091$

0.563

$<0.001 \quad 1.920$

2.204

$0.029-1.642$

$-0.052$

$0.018 \quad 0.139$

1.121

$0.665 \quad 0.762$

1.195

$0.004 \quad 0.757$

1.089

$0.042 \quad 0.582$

0.101

$<0.001 \quad-0.934$

$-0.048$

$0.560 \quad 0.026$

1.567

$<0.001 \quad 0.431$

0.912

$0.006 \quad-0.476$

$-0.087$

$<0.001 \quad 0.182$

0.626

0.018

0.171

0.533

0.761

Adjusted

squared

0.672

0.582

$-0.11$

0.222

0.478

$-0.167$

0.125

0.496

0.318

0.297

0.215

$-0.011$

0.218

0.779

0.540

$-0.345$

0.270

0.048

$-5.272$

$-0.091$

$0.022 \quad 0.839$

$-0.162$

0.001

0.187

0.742

$0.001 \quad-2.377$

$-0.132$

$\begin{array}{lll}0.560 & 0.106 & 1.567\end{array}$

$0.010 \quad 0.332$

0.866

$<0.001 \quad 1.920$

2.204

$0.018 \quad 0.139$

1.121

$0.046 \quad 0.186$

1.267

$0.016 \quad 0.762$

1.195

$0.004 \quad 0.757$

1.089

$<0.001 \quad 0.101$

$0.036 \quad 0.230$

1.260

$<0.001 \quad-1.340$

$-0.138$

$<0.001 \quad 0.170$

1.252

0.584

0.672

$-0.310$

$-0.122$

$\begin{array}{lll}0.048 & -5.272 & -0.091 \\ 0.022 & -0.756 & -0.108\end{array}$

Page 21/23 


\begin{tabular}{|c|c|c|c|c|c|}
\hline Hospital type (private vs public) & -0.067 & 0.001 & -1.277 & -0.037 & \\
\hline Gender (female vs male) & 0.123 & 0.029 & 0.052 & 1.642 & \\
\hline Health condition (bad vs good0 & 0.297 & 0.018 & 0.139 & 1.121 & \\
\hline Working in the frontline & 0.379 & $<0.001$ & 0.101 & 0.582 & \\
\hline Diagnosed as COVID19 case (yes vs no) & -0.198 & 0.002 & -0.613 & -0.152 & \\
\hline Colleague diagnosed with COVID19 (yes vs no) & 0.325 & 0.008 & 0.187 & 0.457 & \\
\hline Threat perception scale & 1.241 & 0.027 & 0.492 & 2.387 & \\
\hline Fear of COVID-19 & 1.055 & $<0.001$ & 0.842 & 1.568 & \\
\hline Altruistic (yes vs no) & -0.418 & 0.023 & -0.753 & -0.215 & \\
\hline Low income & 2.317 & $<0.001$ & 1.017 & 4.213 & \\
\hline Previous experience of working in outbreaks & -0.093 & 0.007 & -0.325 & -0.034 & \\
\hline Fear of COVID-19 & 1.993 & 0.002 & 0.916 & 3.018 & \\
\hline IFDFW scale & -0.292 & 0.004 & -0.456 & -0.126 & \\
\hline Extensive working hours & 1.671 & 0.027 & 0.814 & 3.543 & \\
\hline Correlates of client-related burnout & & & & & 0.632 \\
\hline Age $(>40$ y vs $\leq 40$ y) & -0.163 & $<0.001$ & -0.453 & -0.128 & \\
\hline year of experience (large vs small) & -0.291 & $<0.001$ & -0.376 & -0.130 & \\
\hline Threat perception scale & 1.953 & $<0.001$ & 1.543 & 2.712 & \\
\hline Altruistic (yes vs no) & -0.267 & $<0.001$ & -1.312 & -0.106 & \\
\hline Low income & 0.616 & $<0.001$ & 0.523 & 1.812 & \\
\hline Previous experience of working in outbreaks & -0.112 & 0.007 & -0.820 & -0.065 & \\
\hline Fear of COVID-19 & 1.431 & 0.018 & 1.054 & 2.617 & \\
\hline IFDFW scale & -0.104 & $<0.001$ & -0.298 & -0.076 & \\
\hline
\end{tabular}

Linear regression using stepwise method

\section{Figures}

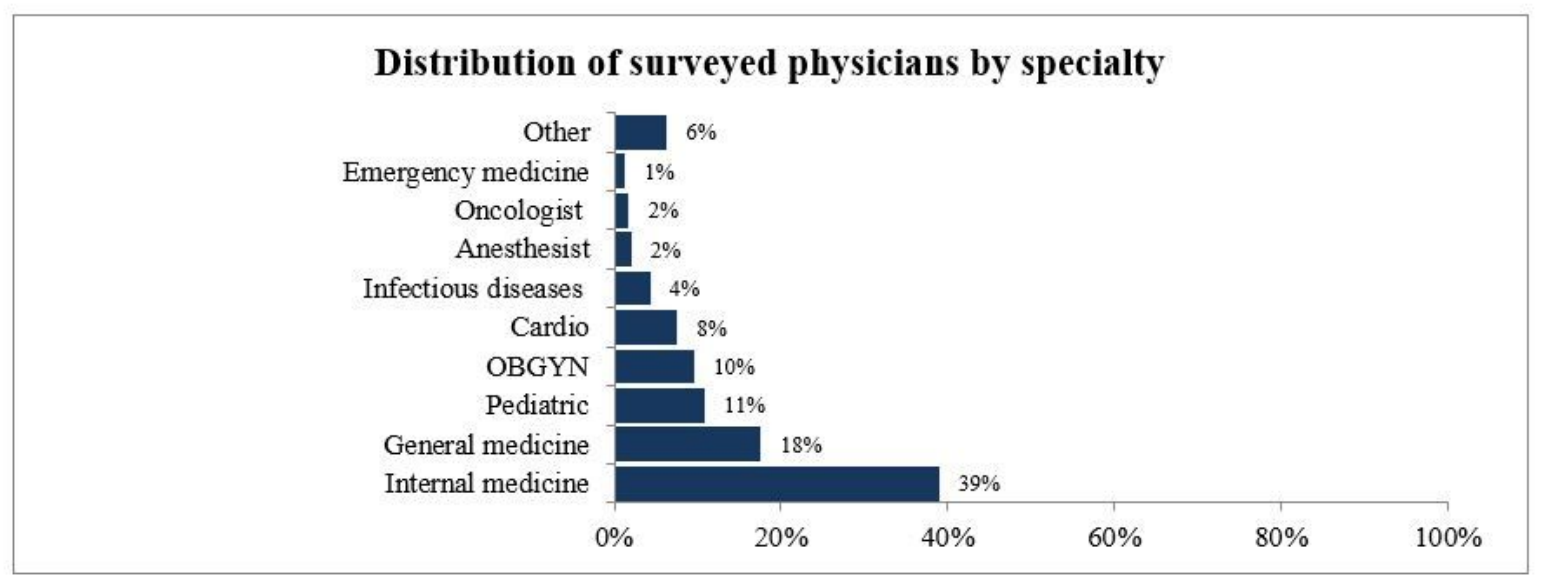

Figure 1

Distribution of surveyed physicians by specialty 


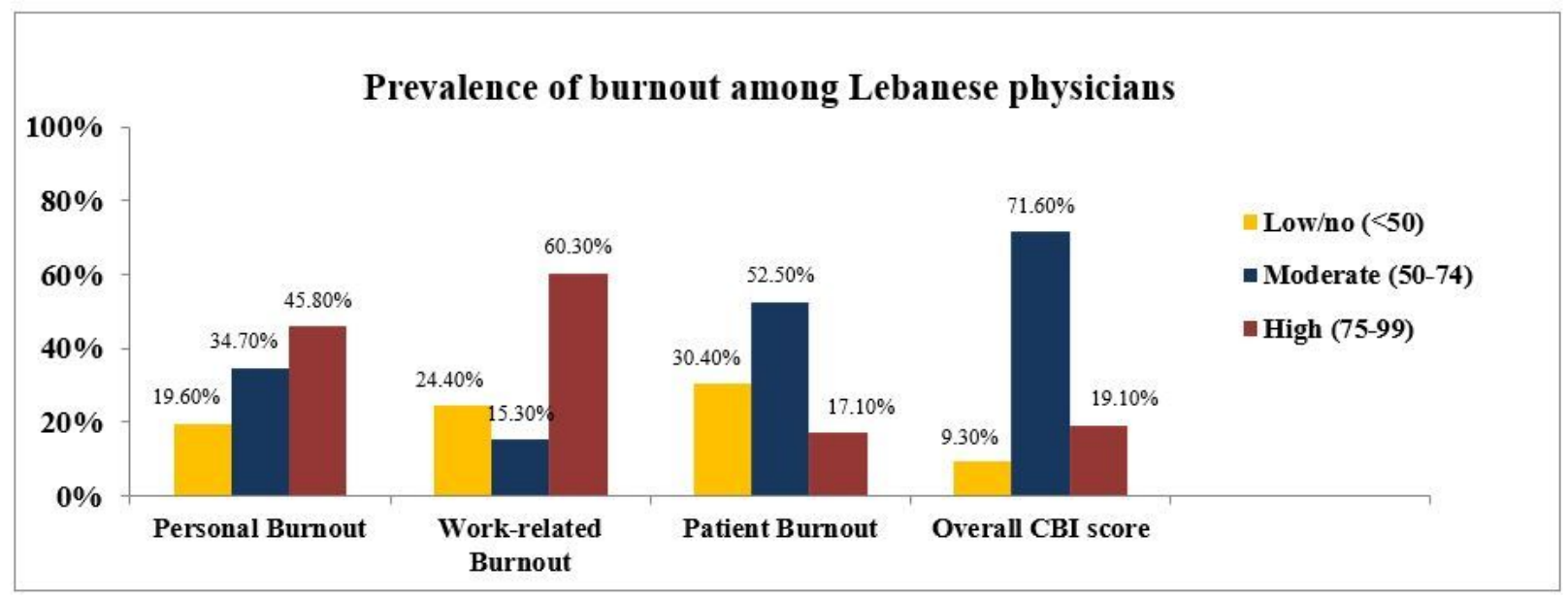

Figure 2

Prevalence of burnout and its three dimensions among Lebanese physicians

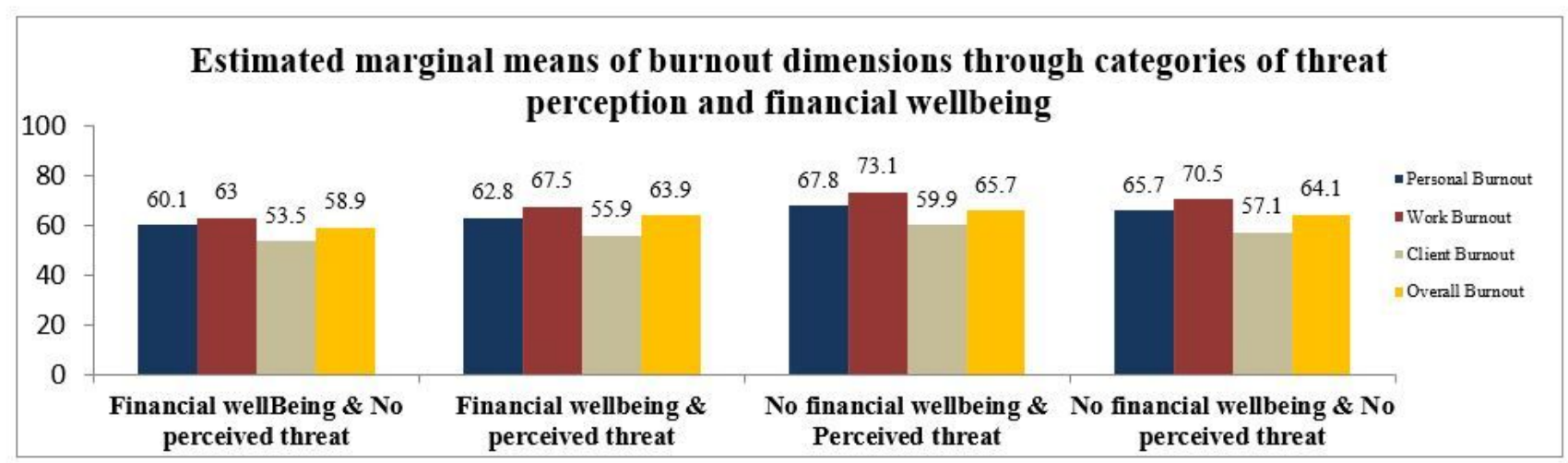

Figure 3

Estimated marginal means of burnout and its dimensions through categories of threat perception scale (low and high) and financial wellbeing (IFDFW).

\section{Supplementary Files}

This is a list of supplementary files associated with this preprint. Click to download.

- Listofabbreviations.docx 